\title{
EFEITO DO CONDICIONAMENTO FISIOLÓGICO E DA PELETIZAÇÃO COM Bacillus subtilis NO DESENVOLVIMENTO DE PASTAGEM
}

Antonio Emilio Rodrigues Manrique ${ }^{1}$; Rita de Cássia Lima Mazzuchelli ${ }^{1}$; Fabio Fernando de Araujo ${ }^{2}$.

1 Mestrando do Curso de Mestrado em Agronomia UNOESTE. ${ }^{2}$ Docente da UNOESTE. E-mail: aer_manrique@hotmail.com

\section{RESUMO}

A aplicação bem sucedida de microrganismos nas sementes de uma forma comercialmente viável é apenas o primeiro passo para a utilização de microrganismos benéficos para melhorar o desenvolvimento das plantas. É igualmente importante que os microrganismos permaneçam viáveis e capazes de colonizar as raízes e rizosfera, a fim de continuar a melhorar o crescimento das plantas. O objetivo do presente trabalho foi avaliar o efeito da inoculação de Bacillus subtilis em sementes de braquiária, utilizando-se das técnicas de revestimento e "bio-priming", no desenvolvimento das plantas em casa de vegetação Foram avaliadas duas formas de revestimento de sementes com formulação de Bacillus sp.; buscando-se investigar acúmulo de biomassa das plantas em casa de vegetação. 0 experimento foi constituído de um esquema fatorial $5 \times 2 \times 3$ ( 5 tipos de revestimento, 2 tratamentos biológicos (isolados bacterianos) e 3 períodos de cortes das plantas (40, 80 e 120 dias), em delineamento inteiramente casualizado com quatro repetições.

Palavras-chave: Brachiaria brizantha; gramíneas; massa seca; rizobactéria; promoção de crescimento.

\section{INTRODUÇÃO}

A influência das rizobactérias no crescimento das plantas tem sido atribuída a efeitos indiretos associado ao controle biológico de patógenos secundários (ARAUJO et al. 2005). No entanto, em alguns trabalhos, observou-se que a promoção de crescimento de plantas, por rizobactérias, também tem sido relacionada à produção de fitohormônios (auxinas) e enzimas líticas (VASSILEV et al., 2006).

Poucos estudos foram conduzidos com a inoculação de sementes de pastagens com rizobactérias promotoras de crescimento, contudo Itzigsohn et al. (2000) mostraram que a inoculação da bactéria diazotrófica Azospirillum spp. em pastagens tem grande potencial para tornar-se uma técnica aplicável, principalmente em condições de déficit hídrico e/ou baixa fertilidade. Nestas situações rizobactérias que produzem hormônios podem mudar a morfologia radicular e aumentar sua biomassa, ampliando com isto a capacidade de exploração do solo (MALIK et al., 1997). Araujo (2008), em estudo de inoculação de Bacillus subtilis em diferentes culturas, verificou que a inoculação aumentou significativamente o teor de nitrogênio no tecido foliar de milho, mesmo considerando que a espécie bacteriana introduzida não é diazotrófica, ou 
seja não é fixadora de nitrogênio, porém já foi caracterizada como produtora de hormônios (Araújo et al. 2005).

A agregação de valor às sementes de Brachiaria spp., utilizando-se métodos e tecnologias de beneficiamento de sementes como a do revestimento, é uma exigência de um mercado cada vez mais competitivo. O revestimento de sementes consiste na deposição de um material seco, inerte e um material cimentante (adesivo) à superfície da semente, permitindo a modificação ou não da forma e tamanho da semente (SILVA et al., 2002).

A utilização de sementes revestidas possibilita a redução dos custos de produção de mudas, diminuindo o consumo de sementes, facilita a mecanização da semeadura, além de proporcionar melhorias na sanidade das sementes e no estabelecimento das plântulas através da incorporação de nutrientes, reguladores de crescimento e outros agroquímicos (SILVA et al., 2002; BONOME, 2003). Como também existe a possibilidade de inoculação de microrganismos benéficos para as plantas. Nesse caso, podemos estudar as rizobactérias promotoras do crescimento de plantas (RPCPs), que são com freqüências isoladas da rizosfera de diversas plantas cultivadas. Entre os gêneros mais estudados destacam-se: Bacillus, Pseudomonas, Azospirillum e Rhizobium. Os efeitos desses microrganismos sobre o desenvolvimento das plantas são amplos, incluindo os efeitos benéficos na germinação de sementes, emergência de plântulas e crescimento das plantas (FIGUEIREDO et al., 2010).

A aplicação bem sucedida de microorganismos nas sementes de uma forma comercialmente viável é apenas o primeiro passo para a utilização de microrganismos benéficos visando melhoria ao desenvolvimento das plantas. É igualmente importante que os microrganismos permanecam viáveis e capazes de colonizar as raízes e rizosfera, a fim de continuar a melhorar o crescimento das plantas. Muitos trabalhos tem sido realizados sobre a aplicação de microorganismos em sementes utilizando-se de várias técnicas, como o uso de suspensões, pastas, pós, turfa ou encapsulamento (MCQUILKEN et al, 1998;. WALKER et al. , 2004). O revestimento de sementes, além da melhoria na uniformidade física e do tamanho das sementes visando uma melhoria na distribuição em semeadura direta, pode proporcionar vantagens adicionais na utilização, de insumos benéficos, como nutrientes e inoculantes (MACHADO, 2000). No entanto, a sobrevivência e estabelecimento de microrganismos benéficos na rizosfera após o revestimento das sementes utilizando-se de diferentes técnicas ainda é pouco estudado. 
O objetivo do presente trabalho foi avaliar o efeito da inoculação de Bacillus subtilis em sementes de braquiária, utilizando-se das técnicas de revestimento e "bio-priming", avaliando-se o armazenamento e germinação de sementes como também o desenvolvimento das plantas em laboratório e casa de vegetação.

\section{METODOLOGIA}

O estudo foi realizado na Casa de Vegetação da Faculdade de Ciências Agrárias da UNOESTE. Foram utilizados dois lotes de sementes sem escarificação de Brachiaria brizantha (Hochst ex A. Rich.) Stapf. cultivar Marandu. O lote 1 era de sementes mais novas e o lote dois de sementes mais velhas. Foram utilizadas duas cepas de Bacillus sp. (5B e AP-3) pertencentes à coleção de microrganismos do Laboratório de Microbiologia da UNOESTE. Sendo que uma cepa de Bacillus sp. denominada de 5B foi isolada de solo em áreas de pastagens e caracterizados como promotora de crescimento de Brachiaria brizantha (ARAUJO et al., 2012) e a outra cepa de Bacillus subtilis (AP-3) foi isolada de área de produção de grãos e está descrito em Araujo et al. (2005).

Após a multiplicação das bactérias em meio de cultura, as células foram separadas por centrifugação (5000 g) e ressuspendidas em meio de acordo com os tratamentos a serem efetuados nas sementes. Todas as suspensões foram ajustadas para $1,0 \times 108$ unidades formadoras de colônia (ufc) por $\mathrm{mL}$. Foi realizado o revestimento de 2,0 g de sementes de braquiária utilizando-se 500 uL de suspensão de células em solução de 1,5\% de methylcelulose, que foram misturadas em tambor rotativo. Para secagem do líquido remanescente $2,0 \mathrm{~g}$ de talco foi adicionado até uniformidade do revestimento na semente. Para efetivação do "bio-priming", 2,0 g de sementes foram incubadas em erlenmeyers com suspensão de células contendo $0,85 \%$ de cloreto de sódio por 12 horas a 20 C. Os recipientes foram mantidos em agitação (120 rpm) durante a incubação. Paralelamente foram conduzidos tratamentos apenas com o cloreto de sódio ("priming") e talco (revestimento) como controles. Por último, as sementes foram secas por 24 horas a 30 ㅇ C até umidade de aproximadamente $5 \%$. Com esses procedimentos ficarão estabelecidos cinco tratamentos: dois com revestimentos e bactérias, dois com apenas revestimentos e um controle sem revestimento.

Experimento de casa de vegetação: O experimento foi conduzido durante 120 dias objetivando-se avaliar o crescimento de Brachiaria brizantha cv. Marandú. Foi utilizado um argissolo vermelho distroférrico oriundo de área de pastagens no município de Presidente Prudente, coletado na camada $0-20 \mathrm{~cm}$ de profundidade, seco ao ar e passado em peneira $(2 \mathrm{~mm})$. 
O solo foi utilizado para preenchimento de vasos de $4 \mathrm{dm}^{3}$. Os vasos foram irrigados diariamente para manter a umidade do solo próximo à capacidade de campo.

Para semeadura foi utilizado dez sementes por vaso. Após a emergência das plantas foi realizado o desbaste deixando-se duas plantas por vaso. O delineamento experimental empregado foi inteiramente casualizado utilizando o esquema de parcelas subdivididas no tempo ("Split plot in time") com onze tratamentos ( 2 isolados $x 5$ revestimentos + controle), três cortes e quatro repetições.

O período experimental iniciou-se com o corte de uniformização, aos 40 dias após a semeadura, deixando-se as plantas com altura aproximada de $5 \mathrm{~cm}$. Após isto foram efetuados três cortes, a $10 \mathrm{~cm}$ de altura da superfície do solo, a cada 45 dias, para avaliar o número de perfilhos por vaso, e matéria seca da parte aérea (por secagem em estufa à 65 ํㅡ) com circulação de ar até obtenção de massa constante.

Os dados obtidos foram submetidos à análise de variância, onde a causa de variação época do corte foi considerada como tratamento secundário, não sendo considerado como uma variável independente na análise estatística (Banzatto; Kronka, 1992) e quando houve diferença significativa a $5 \%$ de probabilidade pelo teste $F$, será aplicado o teste Scott-Knott para comparação das médias dos tratamentos.

\section{RESULTADOS}

A avaliação da massa seca da parte aérea do primeiro lote de sementes (Tabela 1), mostrou que no primeiro corte das plantas, todos os tratamentos realizados diferiram significativamente do controle. Os tratamentos com priming, biopriming com Bacillus subtilis AP-3 e Bacillus subtilis 5B, se mostraram mais eficientes no desenvolvimento da parte aérea de Brachiaria brizantha. No segundo corte realizado houve um menor desenvolvimento das plantas com os tratamentos com o Bacillus subtilis AP-3, em revestimento e biopriming.

$\mathrm{Na}$ ocasião do terceiro corte podemos observar um melhor desenvolvimento das plantas submetidas aos tratamentos revestimento, priming, revestimento com Bacillus subtilis 5B e controle. 
Tabela 1. Desenvolvimento da biomassa da parte aérea de plantas de Brachiaria brizantha do lote 1 após diferentes tratamentos na semente.

\begin{tabular}{lccc}
\hline Tratamentos & $\begin{array}{c}\text { 10 corte } \\
\text { g planta }^{-1}\end{array}$ & $\begin{array}{c}\text { 20 corte } \\
\text { g planta }^{-1}\end{array}$ & $\begin{array}{c}\text { 30 corte } \\
\text { g planta }^{-1}\end{array}$ \\
\hline Controle & $4,10 \mathrm{c}$ & $11,44 \mathrm{a}$ & $7,20 \mathrm{a}$ \\
Revestimento & $5,75 \mathrm{~b}$ & $11,22 \mathrm{a}$ & $8,40 \mathrm{a}$ \\
Priming & $7,81 \mathrm{a}$ & $10,87 \mathrm{a}$ & $8,00 \mathrm{a}$ \\
Revestimento com Bacillus (AP-3) & $5,32 \mathrm{~b}$ & $7,60 \mathrm{~b}$ & $4,93 \mathrm{~b}$ \\
Revestimento com Bacillus (5B) & $5,58 \mathrm{~b}$ & $12,74 \mathrm{a}$ & $8,42 \mathrm{a}$ \\
Biopriming com Bacillus (AP-3) & $7,27 \mathrm{a}$ & $9,05 \mathrm{~b}$ & $5,35 \mathrm{~b}$ \\
Biopriming com Bacillus (5B) & $7,84 \mathrm{a}$ & $11,09 \mathrm{a}$ & $6,40 \mathrm{~b}$ \\
\hline
\end{tabular}

Médias seguidas de mesma letra não diferem estatisticamente pelo teste Scott-Knott (5\%).

A avaliação do segundo lote de sementes (Tabela 2), os tratamentos realizados não proporcionaram diferenças na biomassa da parte aérea das plantas de Brachiaria brizantha no primeiro, segundo e terceiro corte. Na avaliação na ocasião do quarto corte da parte aérea, os tratamentos com revestimento com Bacillus (AP-3) e biopriming com Bacillus (5B), apresentaram um melhor desenvolvimento da biomassa da parte aérea das plantas de Brachiaria brizantha.

A aplicação bem sucedida de microrganismos nas sementes de uma forma comercialmente viável é apenas o primeiro passo para a utilização de microrganismos benéficos visando melhoria ao desenvolvimento das plantas. É igualmente importante que os microrganismos permanecam viáveis e capazes de colonizar as raízes e rizosfera, a fim de continuar a melhorar o crescimento das plantas.

Tabela 2. Desenvolvimento da biomassa da parte aérea de plantas de Brachiaria brizantha do lote 2 após diferentes tratamentos na semente.

\begin{tabular}{lcccc}
\hline Tratamentos & $\begin{array}{l}\text { 10 corte } \\
\text { g planta }\end{array}$ & $\begin{array}{c}\text { 20 corte } \\
\text { g planta }^{-1}\end{array}$ & $\begin{array}{c}\text { 30 corte } \\
\text { g planta }^{-1}\end{array}$ & $\begin{array}{c}\text { 40 corte } \\
\text { g planta }^{-1}\end{array}$ \\
\hline Controle & $1,77 \mathrm{a}$ & $7,61 \mathrm{a}$ & $10,69 \mathrm{a}$ & $7,01 \mathrm{~b}$ \\
Revestimento & $2,01 \mathrm{a}$ & $9,87 \mathrm{a}$ & $10,98 \mathrm{a}$ & $7,92 \mathrm{~b}$ \\
Priming & $2,19 \mathrm{a}$ & $8,41 \mathrm{a}$ & $9,02 \mathrm{a}$ & $6,29 \mathrm{~b}$ \\
Revestim. com Bacillus (AP-3) & $1,78 \mathrm{a}$ & $8,33 \mathrm{a}$ & $11,61 \mathrm{a}$ & $9,39 \mathrm{a}$ \\
Revestim. com Bacillus (5B) & $1,76 \mathrm{a}$ & $9,25 \mathrm{a}$ & $11,02 \mathrm{a}$ & $7,53 \mathrm{~b}$ \\
Biopriming com Bacillus (AP-3) & $2,10 \mathrm{a}$ & $9,52 \mathrm{a}$ & $10,96 \mathrm{a}$ & $7,62 \mathrm{~b}$ \\
Biopriming com Bacillus (5B) & $1,86 \mathrm{a}$ & $8,19 \mathrm{a}$ & $11,05 \mathrm{a}$ & $8,30 \mathrm{a}$ \\
\hline
\end{tabular}

Médias seguidas de mesma letra não diferem estatisticamente pelo teste Scott-Knott (5\%). 


\section{DISCUSSÃO}

Os efeitos desses microrganismos sobre o desenvolvimento das plantas são amplos, incluindo os efeitos benéficos na germinação de sementes, emergência de plântulas e crescimento das plantas (FIGUEIREDO et al., 2010).

A influência das rizobactérias no crescimento das plantas tem sido atribuída a efeitos indiretos associados ao controle biológico de patógenos secundários (Araujo et al., 2005). No entanto, em alguns trabalhos, observou-se que a promoção de crescimento de plantas, por rizobactérias, também tem sido relacionada à produção de fitohormônios (auxinas) e enzimas líticas (VASSILEV et al., 2006).

O revestimento de sementes, proporciona além da melhoria na uniformidade física e do tamanho das sementes visando uma melhoria na distribuição em semeadura direta, pode proporcionar vantagens adicionais na utilização, de insumos benéficos, como nutrientes e inoculantes (MACHADO, 2000).

\section{CONCLUSÃO}

A inoculação da bactéria nas sementes utilizando-se a técnica do priming ou revestimento, mostrou-se como promissora para incrementar o crescimento da Braquiária no último corte efetuado quando utilizou-se as sementes mais velhas.

\section{REFERÊNCIAS}

ARAUJO, F.F.; GUABERTO, L.M.; SILVA, I.F.D. Bioprospection of plant growth promoter rhizobacteria in Brachiaria brizantha. Revista Brasileira de Zootecnia, 41(3): 521-527, 2012. http://dx.doi.org/10.1590/S1516-35982012000300007

ARAUJO, F.F.; HENNING, A.A.; HUNGRIA, M. Phytohormones and antibiotics produced by Bacillus subtilis and their effects on seed pathogenic fungi and on soybean root development. World Journal of Microbiology and Biotechnology, Dordrecht, 21:1639- 1645, 2005. http://dx.doi.org/10.1007/s11274-005-3621-x

BANZATO, D.A; KRONKA, S.N. Experimentação agrícola. 2 ed. Jaboticabal, Funep, 1992. 247p.

BONOME, L.T.S. Condicionamento fisiológico e revestimento de sementes de Brachiaria brizantha cultivar Marandu. 2003. 99p. Dissertação (Mestrado em Agronomia)-Universidade Federal de Lavras, Lavras.

FIGUEIREDO, M.V.B.; SELDIN, L.; ARAUJO, F. F. Plant growth promoting rhizobacteria: Fundamentals and Applications In: Maheshwari, D.K.(ed.) Plant growth and health promoting bacteria.1 ed.Berlin: Springer-Verlag, 18:45-68, 2010. 
ITZIGSOHN, R.; BURDMAN, S.; OKON, Y. et al. Plant-growth promotion in natural pastures by inoculation with Azospirillum brasilense under suboptimal growth conditions. Arid Soil Research, v.13, p.151-158, 2000. http://dx.doi.org/10.1080/089030600263076

MACHADO, J. C. Tratamento de sementes no controle de doenças. Lavras: LAPS/UFLA/FAEPE, 2000, 138p.

MALIK, K.A.; RAKHSHANDA, B., MEHNAZ, S. et al. Association of nitrogen-fixing plant-growth promoting rhizobacteria (PGPR) with kallar grass and rice. Plant Soil, v. 194, p.37-44, 1997. http://dx.doi.org/10.1023/A:1004295714181

MCQUILKEN, M.P., HALMER, P., RHODES, D.J. Application of microorganisms to seeds. In: Burges, H.D. (Ed.), Formulation of Microbial Biopesticides: Beneficial Microorganisms, Nematodes and Seed Treatments. Kluwer Academic Publishers., Dordrecht, pp. 255-285. 1998. http://dx.doi.org/10.1007/978-94-011-4926-6 8

SILVA, J.B.C.; SANTOS, P.E.C.; NASCIMENTO, W.M. Desempenho de sementes peletizadas de alface em função do material cimentante e da temperatura de secagem dos péletes. Horticultura Brasileira, 20:67-70, 2002. http://dx.doi.org/10.1590/S0102-05362002000100013

VASSILEV, N., VASSILEVA, M., NIKOLAEVA, I. Simultaneous P-solubilizing and biocontrol activity of microorganisms: potentials and future trends. Applied Microbiology and Biotechnology 71:137144, 2006. http://dx.doi.org/10.1007/s00253-006-0380-z

WALKER, R., ROSSALL, S., ASHER, M.J.C., 2004. Comparison of application methods to prolong the survival of potential biocontrol bacteria on stored sugar-beet seed. Journal of Applied Microbiology 97, 293-305. http://dx.doi.org/10.1111/i.1365-2672.2004.02318.x 